\title{
Presenilins are required for maintenance of neural stem cells in the developing brain Woo-Young Kim ${ }^{1,2}$ and Jie Shen*1
}

\author{
Address: ${ }^{1}$ Center for Neurologic Diseases, Brigham \& Women's Hospital, Program in Neuroscience, Harvard Medical School, Boston, MA, 02115, \\ USA and ${ }^{2}$ Department of Thoracic/Head and Neck Medical Oncology, The University of Texas M. D. Anderson Cancer Center, Houston, TX, 77030, \\ USA \\ Email: Woo-Young Kim - wkim@mdanderson.org; Jie Shen* - jshen@rics.bwh.harvard.edu \\ * Corresponding author
}

Published: 8 January 2008

Molecular Neurodegeneration 2008, 3:2 doi:10.1186/1750-1326-3-2
Received: 7 November 2007

Accepted: 8 January 2008

This article is available from: http://www.molecularneurodegeneration.com/content/3/1/2

(C) 2008 Kim and Shen; licensee BioMed Central Ltd.

This is an Open Access article distributed under the terms of the Creative Commons Attribution License (http://creativecommons.org/licenses/by/2.0), which permits unrestricted use, distribution, and reproduction in any medium, provided the original work is properly cited.

\begin{abstract}
The early embryonic lethality of mutant mice bearing germ-line deletions of both presenilin genes precluded the study of their functions in neural development. We therefore employed the CreloxP technology to generate presenilin conditional double knockout (PS CDKO) mice, in which expression of both presenilins is inactivated in neural progenitor cells (NPC) or neural stem cells and their derivative neurons and glia beginning at embryonic day II (EII). In PS CDKO mice, dividing NPCs labeled by BrdU are decreased in number beginning at EI3.5. By EI5.5, fewer than $20 \%$ of NPCs remain in PS CDKO mice. The depletion of NPCs is accompanied by severe morphological defects and hemorrhages in the PS CDKO embryonic brain. Interkinetic nuclear migration of NPCs is also disrupted in PS CDKO embryos, as evidenced by displacement of S-phase and M-phase nuclei in the ventricular zone of the telencephalon. Furthermore, the depletion of neural progenitor cells in PS CDKO embryos is due to NPCs exiting cell cycle and differentiating into neurons rather than reentering cell cycle between EI3.5 and EI4.5 following PS inactivation in most NPCs. The length of cell cycle, however, is unchanged in PS CDKO embryos. Expression of Notch target genes, Hes I and Hes5, is significantly decreased in PS cDKO brains, whereas DIII expression is up-regulated, indicating that Notch signaling is effectively blocked by PS inactivation. These findings demonstrate that presenilins are essential for neural progenitor cells to re-enter cell cycle and thus ensure proper expansion of neural progenitor pool during embryonic neural development.
\end{abstract}

\section{Background}

During mammalian neural development, neural progenitor cells (NPCs) divide and populate the progenitor pool in the ventricular zone (VZ) of the developing telencephalon [1]. There are two phases of neurogenesis. The first phase spans from embryonic day 8.5 (E8.5) to 10.5, during which neural progenitor population expands. The second phase commences around E11.5, reaches peak by E15.5, and then diminishes by E17.5, generating most of the cortical neurons through eleven cell cycles [2-6]. During the first phase, neural progenitor cells are columnar, connecting the pial surface and the apical surface, and predominantly undergo symmetric cell division to expand rapidly the self-renewal founder progenitor cells $[6,7]$. During the second phase, neural progenitors in the ventricular zone predominantly undergo asymmetric cell division to generate self-renewal daughter progenitor cells that remain in the cell cycle and committed postmitotic 
neural precursor daughter cells that will ultimately differentiate into neurons or glia [3,7-10]. Notch receptors are required for neural progenitor cell proliferation [11-13]. In the cell cycle of this asymmetric cell division, at the transition from $S$ phase to $M$ phase, the dividing neural progenitor cells displace their nuclei and subsequently migrate from the basal membrane to the apical surface of the neuroepithelium, a phenomenon termed interkinetic nuclear migration (INM) [14,15].

Presenilin-1 (PS1) and presenilin-2 (PS2) are the major causative genes of familiar Alzheimer disease (FAD) [16]. Presenilin (PS) is an essential component of the $\gamma$-secretase complex, and Notch is one of the physiological substrates of $\gamma$-secretase [17]. Notch is one of the most important regulators of neural development in organisms from insects to mammals [18-20]. During mammalian neural development, activation of the Notch signaling pathway is involved in the maintenance of neural progenitor identity and the decision of cell fate [21]. Presenilin is required for Notch signaling during neural development, though expression of Hes1, one of the Notch downstream effector genes, is not suppressed by inactivation of PS1, whereas expression of Hes5 is effectively suppressed [22]. The germ-line deletion of PS1 in mice results in perinatal lethality, cerebral hemorrhages and impairment of neurogenesis, likely due to down-regulation of Notch signaling $[22,23]$. Although no phenotypes have been observed in PS2-null mice [24], earlier and more severe developmental defects are found in PS1/PS2 double knockout mice than in PS1 single knockout mice [25]. This finding suggests functional redundancy between PS1 and PS2 in embryonic development. When PS1 inactivation is restricted to NPC and NPC-derived neurons and glia beginning at $\sim \mathrm{E} 11$ during the second phase of neurogenesis, the NPC-PS1 cKO mice can live up to 2-3 months postnatally. These mice harbor defects in neuronal migration, cortical lamination and radial glial development with milder loss of the progenitor cells [26].

Here we investigate that role of both presenilins in neural development, especially in the maintenance of neural progenitor or stem cell population. We employed a Nestin-Cre transgene to circumvent the early embryonic lethality associated with the germ-line deletion of both PS1 and PS2 loci and to restrict PS inactivation to NPCs and NPC-derived neurons and glia. Using this conditional double knockout mouse model, we found that presenilins are required for neural progenitor cells to re-enter cell cycle and for the expansion of neural progenitor population during embryonic development. Precocious exit of cell cycle observed in PS CDKO mice is accompanied by disruption of interkinetic nuclear migration and is followed by premature differentiation into postmitotic neurons. Blockade of expression of Notch downstream target genes, Hes1 and Hes5, in PS CDKO mice may underlie or contribute to the failure of neural progenitor cells to reenter cell cycle. Thus, presenilins play an essential role for NPCs or neural stem cells to retain their self-renewal capacity to expand the progenitor population.

\section{Results \\ Gradual loss of PS I transcripts in the developing PS CDKO brain}

To determine the spatial and temporal course of PS1 inactivation, we performed in situ hybridization analysis on the neural progenitor cell (NPC)-restricted PS CDKO mice, which were generated by crossing floxed PS1 mice with the Nestin-Cre transgenic mice in the PS2-/- background. We compared the PS1 mRNA expression in PS CDKO (fPS1/fPS1; Nestin-Cre; PS2-/-) embryos and littermate controls (PS2-/-) using a probe specific for PS1 exons 2 and 3. Consistent with our previous report on the analysis of spatial and temporal inactivation of PS1 in NPC-PS1 cKO mice [26], we found a marked reduction of PS1 mRNAs in PS CDKO embryos at E11.5. At E12.5, no significant signal of PS1 mRNAs was detected in the developing telencephalon of PS cDKO embryos. By E13.5, the PS1 mRNA was no longer detectable throughout the brain (data not shown).

\section{Severe reduction of neural progenitor cells in PS CDKO mice}

The NPC-restricted PS cDKO mice die perinatally. After E15.5, the developing PS cDKO brain appeared smaller and grossly abnormal compared with brains from littermate PS2-/-mice, in which no abnormal brain phenotype has been reported [27]. At postnatal day 0 (P0), the PS cDKO brain is much smaller with lower neuronal density and disorganized cortical layers. To assess whether the number of neural progenitor cells in PS CDKO brains was affected, we performed BrdU pulse labeling on comparable brain sections from $P S \mathrm{CDKO}$ and control mice between E12.5 and E17.5. BrdU is an analogue of thymidine, thus labels newly synthesized DNA. In the control brain, BrdU-positive cells in S-phase reside in the deeper layers of the ventricular zone at these developmental stages [4]. At E13.5 the BrdU staining pattern was not noticeably different between control and PS cDKO mice (Figure 1A, B). By E14.5, PS cDKO brains exhibit disrupted BrdU staining pattern in many areas and the lateral ventricle was smaller (Figure 1C, D). At E17.5 the lateral ventricle became hardly visible in the $P S \mathrm{CDKO}$ brain (asterisks in Figure 1E, F), and only a few BrdU-positive progenitor cells remain in the ganglionic eminence (GE) of the mutant cortex (black arrowheads in Figure 1E, F). Severe hemorrhages were also observed in all of the PS cDKO brains after E15.5. Many blood-originated, non neuronal staining were found in the mutant brain (open arrowheads in Figure 1F, compare the insets in Figure 1E, 

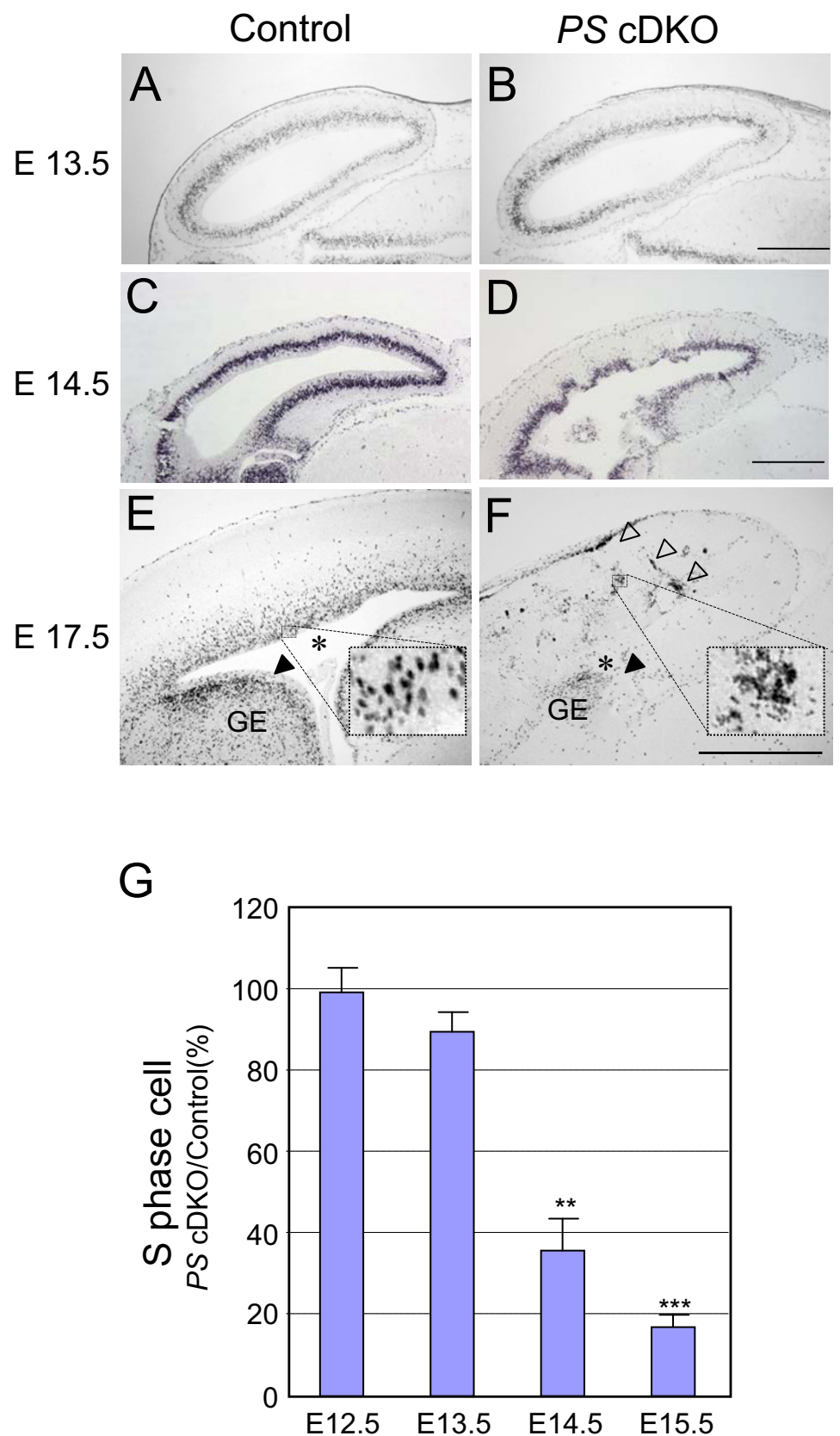

Figure I

Depletion of neural progenitor cells in the PS cDKO embryonic brain. (A-F) Proliferating (S-pahse) neural progenitors are identified by BrdU labeling at EI3.5, EI4.5 and EI7.5. While the BrdU staining pattern does not differ between PS CDKO and control embryonic brains at EI3.5 (A, B), severe morphological abnormalities of BrdU stained progenitor cells are present in PS CDKO brains at EI4.5 (C, D). By EI7.5, only a few proliferating neural progenitor cells remain in the lateral ganglionic eminence (GE, black arrowheads), whereas in the ventricular zone of the telencephalon neural progenitor cells are almost completely depleted in the PS CDKO mice brain. Many non-neuronal, unnucleated, clotted and small staining are found in the PS CDKO brain (opened arrow heads and inset in F). The lateral ventricle (labeled with an asterisk in the control brain) is missing in PS cDKO brains (E, F). The insets in E, F are the high power view of boxed area. Scale bar: $500 \mu \mathrm{m}$. (G) Quantification of BrdU-labeled S-phase cells. BrdU-positive cells were counted at EI2.5, EI3.5, EI4.5, and EI5.5, and the percentage of BrdU-positive cells in PS cDKO embryos to that in the control is shown. Significant reductions of BrdU-positive cells are detected at EI4.5 and EI5.5 in PS cDKO mice (**, $\mathrm{p}<0.0 \mathrm{I} ; * * *, \mathrm{p}<0.00 \mathrm{I})$. 
F). The number of BrdU-positive progenitor cells in the telencephalon of PS cDKO mice was normal at E12.5 $(99.3 \pm 6.2 \%)$ and slightly reduced at E13.5 (89.5 $\pm 4.8 \%$; Figure 1G). By E14.5 and E15.5, the number of BrdU-positive progenitor cells was further decreased in the PS cDKO brains (E14.5: $35.2 \pm 7.9 \%, \mathrm{p}<0.01$; E15.5: $17.2 \pm$ $2.5 \%, \mathrm{p}<0.001$; Figure $1 \mathrm{G})$. The results demonstrate that inactivation of presenilins causes drastic reduction of dividing neuroprogenitor cells after E13.5.

\section{Disrupted interkinetic nuclear migration of neural progenitor cells in PS cDKO mice}

During the cell cycle neural progenitor cells in the developing forebrain undergo a process termed interkinetic nuclear migration (INM) [28]. We then examined whether inactivation of presenilins affects the INM process. At E12.5 and earlier stages, no difference was observed between PS cDKO and control brains. By E13.5, however, the S-phase nuclei in the mutant mice were detected in abnormal positions; rather than localized in the basal are of the ventricular zone, they are randomly distributed in the ventricular zone and are especially clustered near the ventricle (Figure 2A, B). To quantify the ectopic distribution of the S-phase nuclei, we divided the cortical ventricular zone into 11 bins from the preplate to the ventricle and then counted the number of the S-phase nuclei in each bin (Figure 2E). The quantitative analysis further confirmed the ectopic localization of the S-phase nuclei at this developmental stage. By E14.5, the interkinetic nuclear migration was further disrupted in PS CDKO brains with the S-phase nuclei clustered near the ventricle surface in many places (Figure 2C, D).

We further performed additional immunostaining to determine the localization of the progenitor cell nuclei in M-phase of the cell cycle using phospho-histone 3 (p-histone 3) as a marker. At E13.5, in the control embryo cortex, the p-histone 3-positive nuclei were largely restricted to the ventricular surface (VS), as expected. However, the number of p-histone 3-positive nuclei localized at the basal are of ventricular zone (non-ventricular M-phase nuclei) was significantly higher in $P S$ cDKO mice (Figure $3 \mathrm{~A}, \mathrm{~B}$ and $3 \mathrm{I}, 24.0 \pm 2.1 \%$ for control and $49.4 \pm 3.6 \%$ for $P S \mathrm{cDKO}, \mathrm{p}<0.001)$. However, the total number of $\mathrm{M}$ phase cells was unchanged at this time $(39.7 \pm 4.2$ for control, $37.8 \pm 3.1$ for PS cDKO), similarly to S-phase cells we observed (Figure 1). The Tuj-1 staining showed a broader staining pattern in PS cDKO mice, indicative of excessive neuronal differentiation (Figure 3C and 3D). In PS cDKO mice, the p-histone 3-positive nuclei were found in the Tuj-1-positive zone, suggesting precocious differentiation of the progenitor cells to neurons and the disruption of the boundary between the ventricular zone and the preplate. This genotypic difference became more profound in embryos at E14.5, when much fewer p-histone 3-positive nuclei were present in PS cDKO $(17.3 \pm 2.7)$ embryos than in the control $(44.2 \pm 7.9, \mathrm{p}<0.5)$. Furthermore, a higher percentage of the p-histone 3-positive nuclei were localized at the basal are of ventricular zone in PS cDKO mice $(61.6 \pm 4.9 \%)$, compared to the control $(20.1 \pm$ $2.4 \%, \mathrm{p}<0.001$; Figure 3E, F, and 3J). The Tuj-1-positive cells cover most of the ventricular zone at this stage in PS cDKO mice (Figure $3 \mathrm{G}$ and $3 \mathrm{H}$ ). These results demonstrate the disruption of interkinetic nuclear migration of neural progenitor cells in PS cDKO mice.

\section{Premature exit of the cell cycle in neural progenitor cells of PS cDKO mice}

To determine whether the decrease in the progenitor cells and the disruption of INM result from the progenitors exiting the cell cycle to differentiate rather than re-entering the cell cycle, we examined the cell cycle exit and reentry by calculating the fraction of the cells remaining in the cell cycle during the 24-hour time span. BrdU was used to label dividing progenitor cells at the time of injection, and Ki67 immunoreactivity was used to mark cells that remain in the cell cycle 24 hours later. Thus, dividing cells labeled by BrdU that have left the cell cycle are BrdU+/Ki67- (green), whereas dividing cells that remain in the cell cycle are BrdU+/Ki67+ (yellow in Figure 4A-H). At E13.5, the percentage of the progenitor cells remaining in the cell cycle 24 hours after the BrdU injection at E12.5 is lower in PS cDKO mice (40.2\% $\pm 1.6 \%)$, compared to that in the control $(56.2 \% \pm 1.9 \%, \mathrm{p}<0.01$; Figure $4 \mathrm{I})$. At E14.5, the percentage of the cells remaining in the cell cycle 24 hours after BrdU injection is further decreased in PS cDKO mice $(9.8 \% \pm 0.5 \%)$, relative to the control $(28.4 \% \pm 5.1 \%, \mathrm{p}<0.05)$ (Figure $4 \mathrm{~J})$. Therefore, in the absence of PS, most progenitor cells exit the cell cycle and differentiate into neurons rather than remain as dividing progenitor cells, resulting in depletion of progenitor cells in PS cDKO mice.

The result that greater proportion of progenitor cells at E13.5 and E14.5 fail to reenter cell cycle and differentiate into postmitotic neurons in PS $\mathrm{CDKO}$ mice prompted us to examine whether the length of the cell cycle in the mutant is changed, as the longer cell cycle could complicate the interpretation of the results. We investigated the cell cycle kinetics of the embryos at E13.5, when the neural progenitor cell number is not changed significantly in $P S$ cDKO mice. Pregnant mice were given repeated injections of BrdU to label cumulatively the proliferating population. The proportions of BrdU-labeled cells in the proliferating zone after different lengths of exposure to BrdU were plotted in Figure 5A. Using the model described by Nowakowski et al. [29] and used by others $[4,5,14]$, these data can be interpreted as summarized in Figure $5 \mathrm{~B}$ to give the proportion of cells in the proliferate zone that are actually proliferating (i.e. the growth frac- 
Control
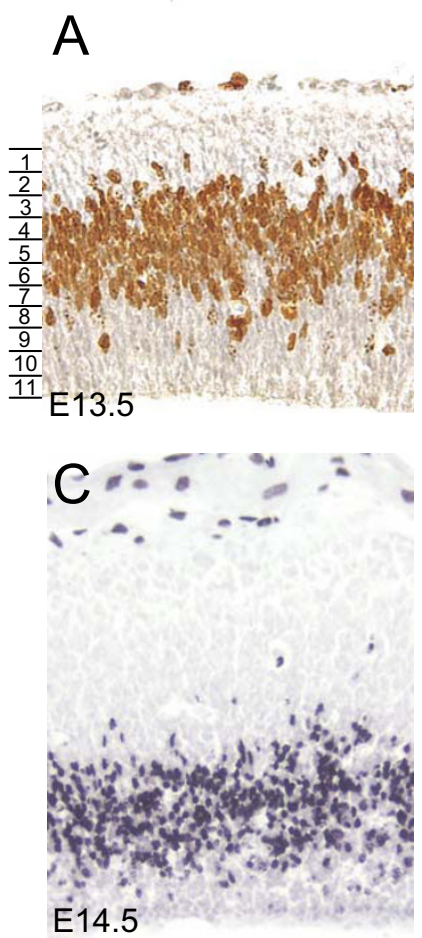

$E$



\section{Figure 2}

Ectopic localization of S-phase nuclei in the ventricular zone of PS cDKO brains. (A, B) At EI3.5, in control brains, the BrdU-positive nuclei are localized in the upper ventricular zone closer to the preplate, whereas in PS CDKO brains, they are distributed more broadly and predominantly in the lower ventricular zone closer to the ventricle, suggesting disrupted interkinetic nuclear migration. (C, D) At EI 4.5, in PS CDKO brains, the BrdU-positive nuclei are absent in many areas of the ventricular zone and are distributed close to the lateral ventricle. (E) The ventricular zone that contains BrdU-positive cells is divided by II bins (I5 $\mu \mathrm{m} / \mathrm{bin})$. Bin I is the layer closest to the preplate (PP), whereas bin II is the layer closest to the lateral ventricle (LV). $n=5$ for the controls and $n=6$ for PS CDKO embryos. Scale bar: $100 \mu \mathrm{m}$ in all figures. 


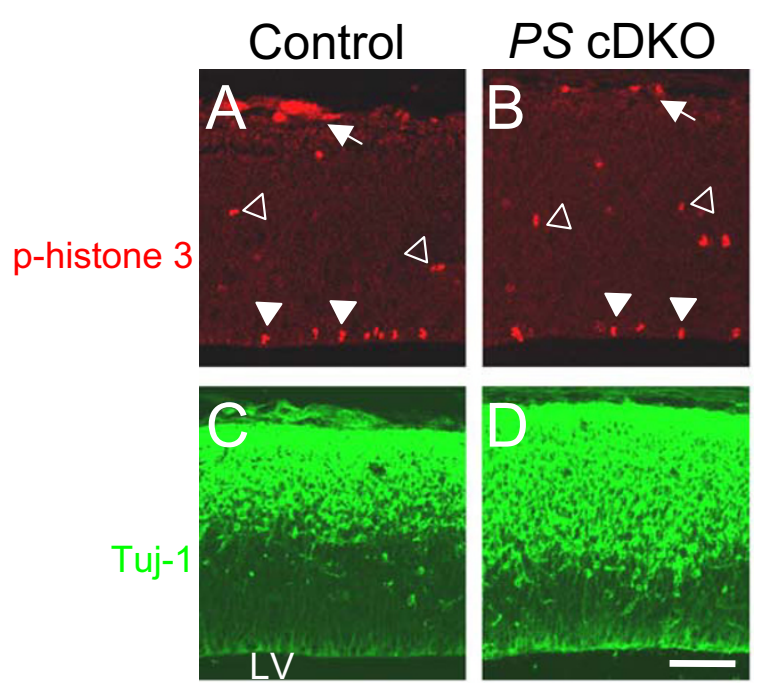

E13.5
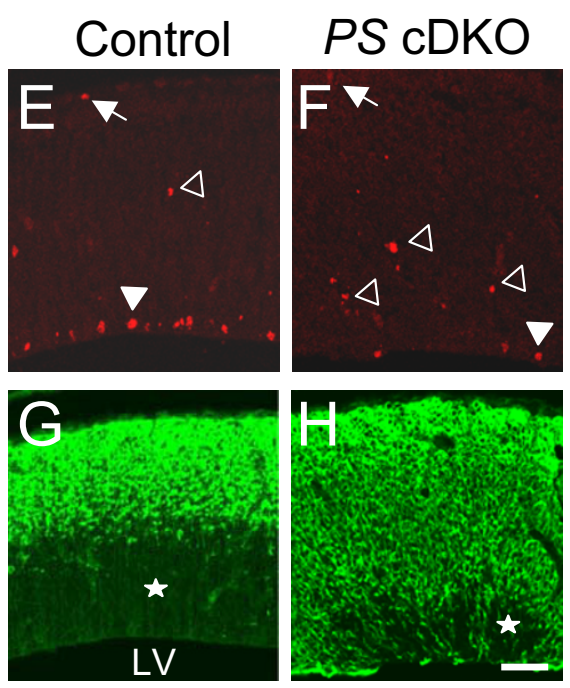

E14.5


Figure 3

Displacement of M-phase nuclei in the ventricular zone of PS cDKO brains. (A-H) Phospho-histone 3 (p-histone 3 , red) is used as a marker for cells in M-phase (A, B, E, F), whereas Tuj-I (green) is used as an early neuronal marker (C, D, G, $H$ ). While the majority of the M-phase nuclei are found in the ventricular surface (closed arrowheads) of the control brain, many M-phase nuclei are found in basal are of the ventricular zone (opened arrowheads) in the developing cortical plate of PS CDKO brains at both EI3.5 and EI4.5, where strong Tuj-I-positive neuronal staining is observed. At E I4.5, most parts of the cortex are stained by Tuj-I already in the mutant while clear layers are observed in the control. The pan early neuronal marker stained most area of the PS cDKO brain and only a very small part of the VZ are still left unstained (white star), suggesting that most of the neural progenitor cells are already being differentiated in the PS cDKO brain. The arrows indicate the meningeal cells. Scale bar: $100 \mu \mathrm{m}$. (I, J) Number and the location of p-histone 3 staining in the parasagital section of forebrain $(750 \mu \mathrm{m}$ width). At EI3.5, in the sections the staining number is not different between the genotype. $76.0 \% \pm 2.1 \%$ (SEM) of M-phase nuclei are detected in the VS (ventricular M phase nuclei) and about $24.0 \%$ of the $M$-phase nuclei were found in basal are of ventricular zone (non-ventricular $M$ phase nuclei) in the control brain. $49.4 \% \pm 3.6 \%$ of the $M$-phase staining in the PS cDKO brain are observed in the non-ventricular region, suggesting that the interkinetic nuclear migration is disrupted in the PS cDKO embryonic brain. $n=4$ for each genotype (I). At EI 4.5, the p-histone 3 staining is much less in the PS cDKO embryos than control $(p<0.05) .20 .1 \% \pm 2.4 \%$ of the M-phase nuclei are detected in non ventricular position in the control, whereas $61.6 \% \pm$ $4.9 \%$ of those are in non ventricular position in the PS cDKO; $\mathrm{n}=6$ and 4 for the wild and mutant embryos respectively (J). $(* * *, p<0.001)$. 


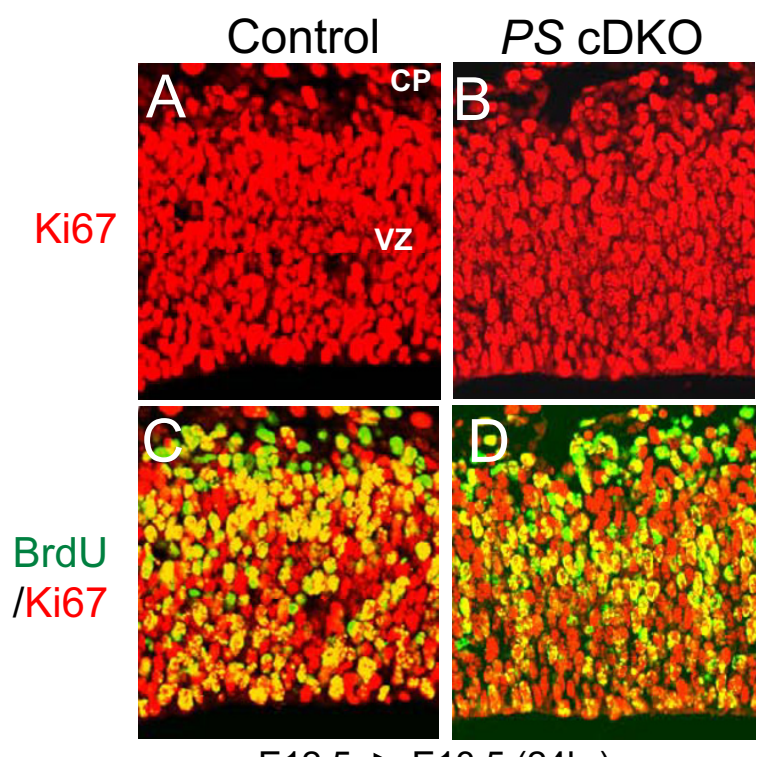

$\mathrm{E} 12.5 \rightarrow \mathrm{E} 13.5(24 \mathrm{hr})$
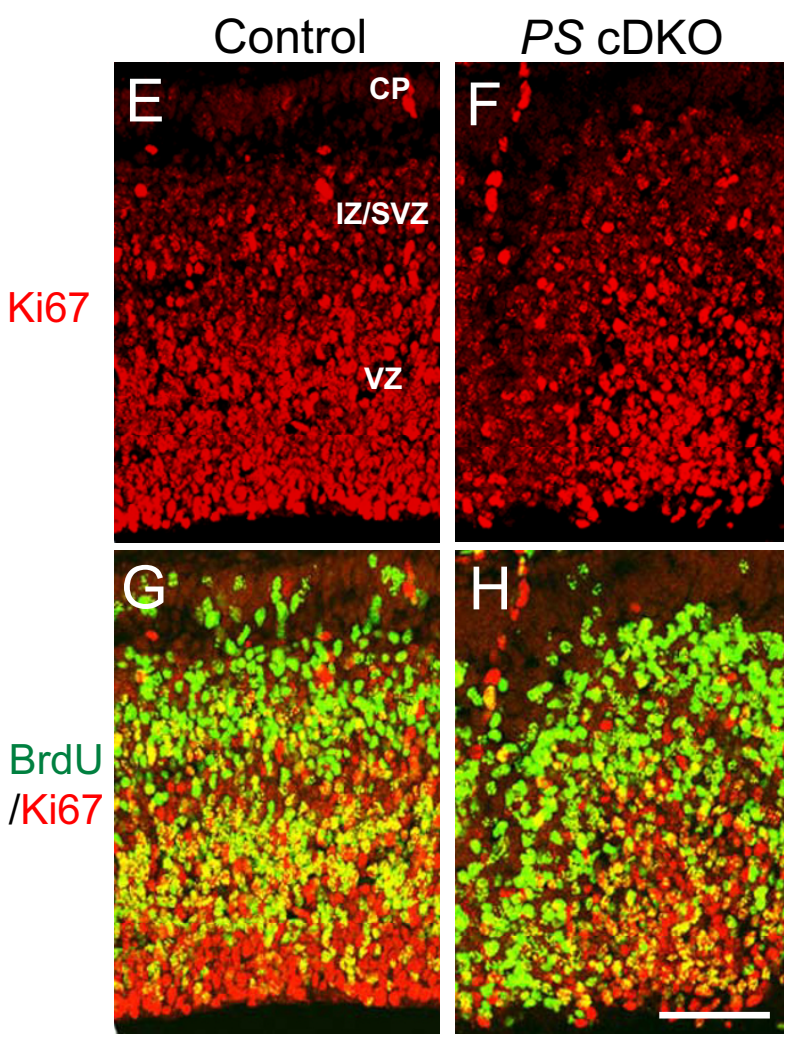

$\mathrm{E} 13.5 \rightarrow \mathrm{E} 14.5(24 \mathrm{hr})$
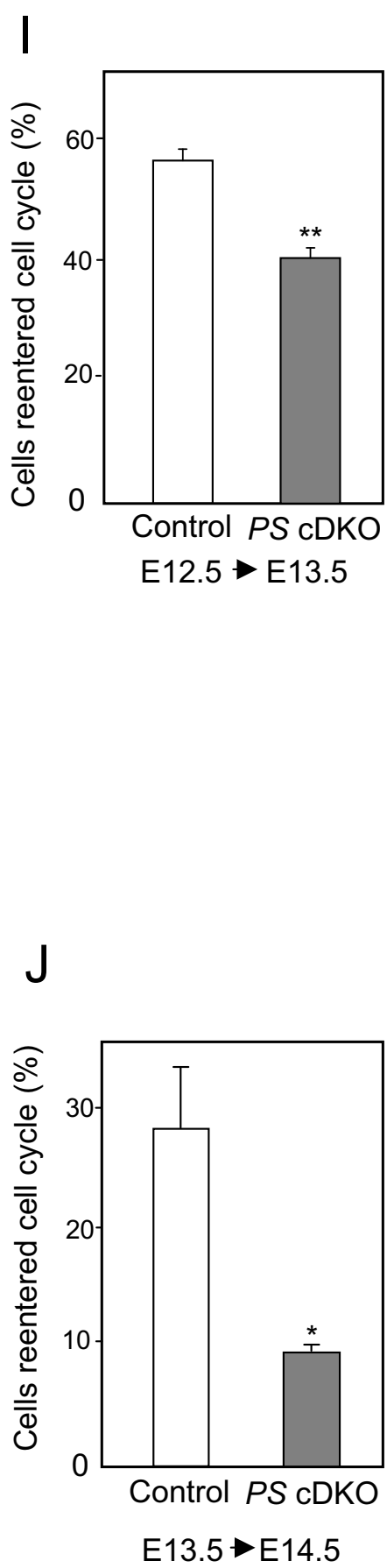

Figure 4

Reduced percentage of neural progenitor cells reentering the cell cycle in PS CDKO embryos. Immunofluorescent staining of $\mathrm{BrdU}$ (green) and the proliferating cell marker Ki67 (red, staining all cell cycle stages except $\mathrm{G}_{0}$ ). (A-D) EI 3.5 embryos labeled by BrdU at EI2.5. (E-H) EI4.5 embryos labeled by BrdU at EI3.5. (I, J) The proportions of cells which reentered cell cycle are shown as (\%). Much less portion of the neural progenitor cells reentered the cell cycle in the PS cDKO embryonic brain $(*, p<0.05)$. Scale bar: $100 \mu \mathrm{m}$. 
A

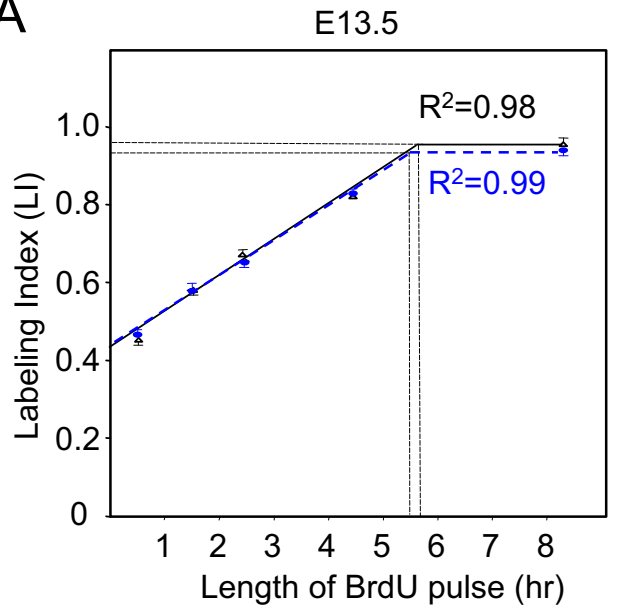

B

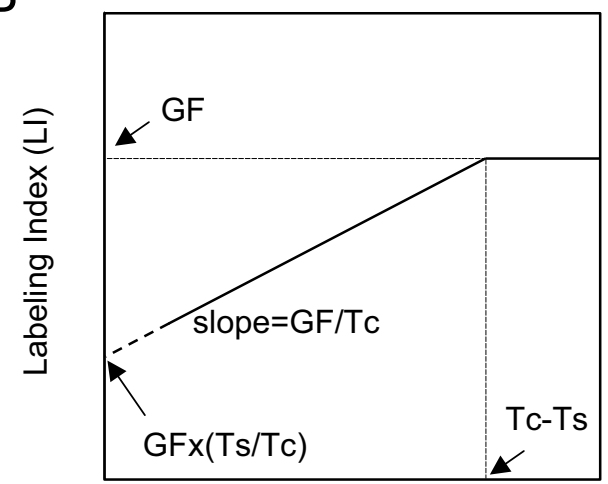

Length of BrdU pulse (hr)

Figure 5

Unchanged cell cycle kinetics in the PS cDKO embryonic brain. (A) Graphs show results of cumulative labeling with BrdU at EI3.5 in PS cDKO (blue dotted line) and control embryos (black line). Least squares fit analysis of these rising phases (excluding data after giving $8.5 \mathrm{~h}$ of BrdU to embryos of both genotypes) yielded the trendlines and $\mathrm{R}^{2}$ values shown. Data points are means \pm SEM of the proportions of BrdU-labeled cells, labeling index (LI), in the cortex of each embryo. (B) The growth fraction (GF), the length of $\mathrm{S}$ phase (Ts) and the length of the cell cycle (Tc) are calculated using the following equations. The intercept on the $y$ axis, $Y_{i}=\mathrm{GF}(\mathrm{Ts} / \mathrm{Tc})$; the time where the GF is maximal $(\mathrm{Tm})$ $=\mathrm{Tc}$-Ts ; the rate of increase (i.e. the slope) of the proportion of labeled cells $=\mathrm{GF} / \mathrm{Tc}$.

tion, GF), the length of the cell cycle (Tc) and the length of $S$ phase (Ts). Previously it was reported that the length of the entire cell cycle and the length of S-phase are longer in PS1-deficient neural precursor cells than in wild-type controls at E14.5 [30]. However, we found that Tc (10.5) and Ts (5.3) in PS cDKO mice were very similar to those of control embryos (11.0 and 5.2, respectively). The Tc and Ts values we obtained in control mice were similar to those reported previously at this age [31]. Therefore we conclude that the cell cycle kinetics was not changed in PS cDKO neural progenitor cells.

\section{Suppression of Notch signaling in the PS cDKO embryonic brain}

We further investigated how Notch signaling is affected in the absence of presenilins. In situ hybridization analysis showed that expression of one of the Notch ligands, Dll1, was increased in PS cDKO mice (Figure 6A, B), similarly as what was observed in PS1-null mice [22]. Furthermore, expression of both Hes 1 and Hes 5 was decreased in the PS cDKO embryonic brain (Figure 6C-F). To quantify the differences, we also performed quantitative real-time RTPCR (Figure 6G). The result showed levels of Dll1 (140.1 $\pm 17.5 \%$, p < 0.05), Hes1 (60.6 $\pm 16.8 \%$, p < 0.01), and Hes5 $(58.5 \pm 9.7 \%, \mathrm{p}<0.05)$ transcripts were changed in the PS cDKO cortex at E13.5, relative to the control $(100 \%)$. Thus, Notch signaling in the developing embryonic brain is more effectively suppressed by inactivation of both PS1 and PS2 in neural progenitor cells than in PS1-null mice [22]. The unchanged expression of Hes1 in PS1-null mice is likely due to the normal expression of PS2, which may compensate for the absence of PS1 on the expression of Hes1 during neural development.

\section{Discussion}

The role of presenilins in the second wave of neurogenesis was not studied previously. The regulation of the interkinetic nuclear migration and asymmetric cell division of the neural progenitor cells in the neocortical development was unclear. Here we demonstrate that neural progenitor cells lacking both presenilins fail to maintain their stem cell identity and self-renewal capacity, resulting in depletion of the progenitor population. The interkinetic nuclear migration of neural progenitor cells is also disrupted in the absence of presenilins and is accompanied by the failure of reentering the cell cycle, which leads to precocious neuronal differentiation. Notch signaling was effectively suppressed by inactivation of both presenilins. Together, these findings have uncovered a critical role of presenilins in the cell cycle regulation of neural progenitor cells and the proper expansion of the progenitor population.

\section{Presenilins in the maintenance of neural progenitor cells through the cell cycle regulation}

Germ-line deletion of the PS1 gene results in precocious neuronal differentiation and the loss of the neural progenitor cells as early as E10.5 [22]. Conditional inactivation of PS1 in neural progenitor cells of NPC-PS1 cKO mice resulted in milder depletion of the progenitor cells, perhaps due to the later onset of PS1 inactivation in PS1 cKO mice compared to PS1-/- mice [26]. In the current study, we circumvented the early embryonic lethality ( $\sim$ E9) exhibited by PS1/PS2-/- mice and restricted inacti- 

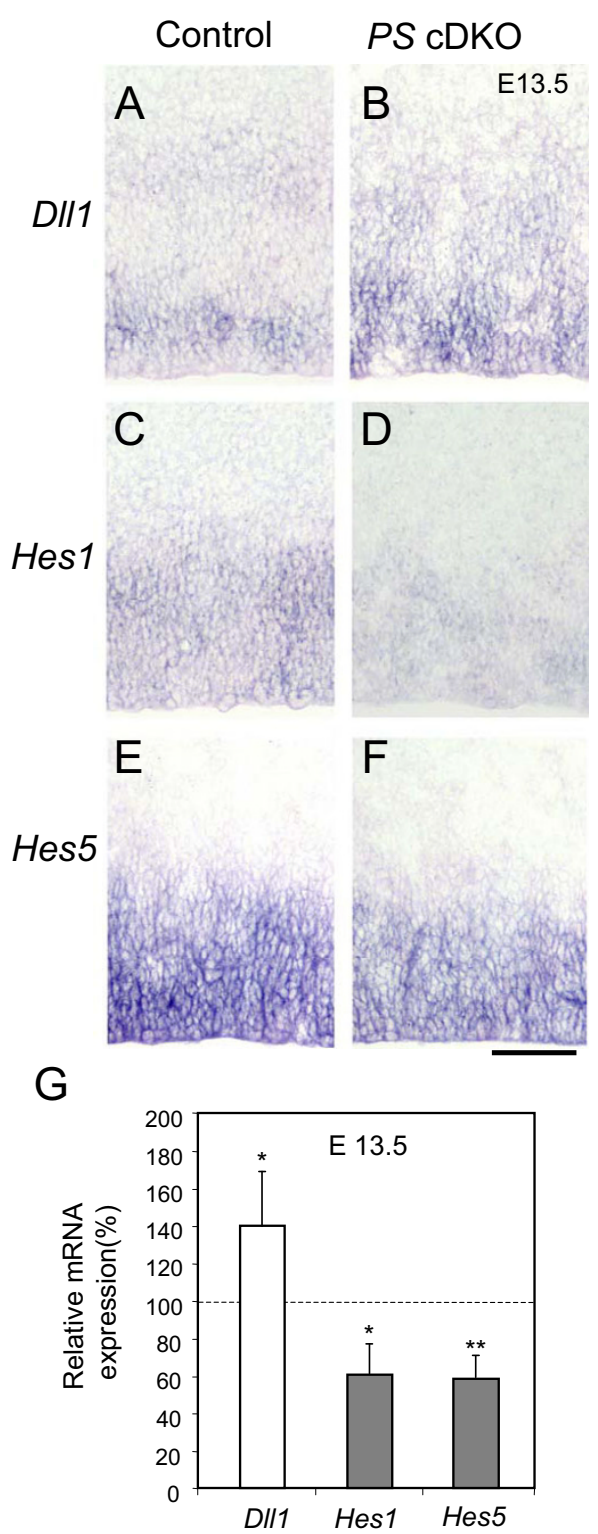

\section{Figure 6}

Suppressed Notch signal in the PS cDKO embryonic brain. The expressions of a notch ligand DIII and two notch downstream target genes, Hes I and Hes5, were examined by in situ hybridization (A-F) and quantitative RT-PCR (G). The comparable EI 3.5 sections from the control and the $P S$ cDKO brain were used. In all parts of the brain, the changes in the expression pattern were similar; the images in the lateral telencephalon are shown. (A, B) The DIII expression was increased in the PS CDKO. (C, D) Hes I was expressed weakly in the control but decreased in the PS CDKO. (E, F) The Hes 5 expression was strong in the control but decreased in the PS CDKO. (G) The expressions of the three genes were examined using real-time quantitative RT-PCR. $n$ $=5$ for each genotype. All RT-PCR results were concordant with the in situ hybridization results (*, $\mathrm{p}<0.05$; **, $\mathrm{p}<0.0 \mathrm{I}$ ). Scale bar: $100 \mu \mathrm{m}$. vation of both PS1 and PS2 to NPCs and NPC-derived cells. Neural progenitor cells in NPC-PS cDKO mice are depleted quickly between E12.5 and E15.5, a duration of about 6.5 cell cycles (the length of the total cell cycle at E13 is about 11 hours, see Figure 5), to only $17.2 \%$ of the control (Figure 1G).

Despite the fact that interkinetic nuclear migration has been a hallmark of vertebrate neural progenitors for seven decades [32], the mechanism underlying INM is not well understood. Currently, little is known about the molecular mechanisms controlling this unique mode of nuclear movement. Here we found that presenilins are required for the regulation of interkinetic nuclear migration (Figures 2 and 3). It was already severely disrupted in PS CDKO mice at E13.5, when the total number of neural progenitor cells was not yet altered. The abnormal location of $\mathrm{M}$ - and S-phase nuclei was also accompanied by the failure of neural progenitor cells reentering the cell cycle and the precocious neuronal differentiation (Figures 3 and 4). Therefore, we conclude that presenilins are required for the control of the INM and for the maintenance of daughter cells in the cell cycle, and that the failure of these processes leads to the depletion of selfrenewable progenitor cell population.

\section{Mechanisms of the cell cycle regulation by presenilins}

Presenilin may regulate the cell cycle through its downregulation of $\beta$-catenin in a $\gamma$-secretase-independent manner, as previously reported $[33,34]$. The transgenic overexpression of $\beta$-catenin in neural progenitor cells promoted these cells to reenter cell cycle, leading to the expansion of NPC population and the enlargement of the developing brain [35]. If presenilins negatively regulate $\beta$-catenin in the developing brain, the elimination of PS in this study may be expected to activate the Wnt signaling by releasing free $\beta$-catenin, a scenario similar to the transgenic overexpression of $\beta$-catenin in the brain [35]. However, NPCs lacking PS exit the cell cycle rather than reenter the cell cycle, resulting in depletion of progenitor cells. In addition, we saw no spinal cord abnormality in our NPC-PS cDKO mice (WYK and JS, unpublished data), whereas a previous report found elevated nuclear $\beta$-catenin in PS1null mice and enhanced cell division in the spinal cord [34]. Therefore, at least for the developmental stages we have studied, the cell cycle dysregulation in the PS CDKO mice is unlikely through $\beta$-catenin.

A large number of substrates for presenilin-mediated $\gamma$ secretase activity have been reported [36]. Loss of the enzymatic activity may contribute the dysregulation of cell cycle in the PS CDKO mice Notch is one of the physiological substrates of $\gamma$-secretase and is required for the proliferation and survival of NPCs or neural stem cells $[11,13,37,38]$. The severe depletion of neural progenitor 
cells in NPC-PS cDKO mice in the current study is consistent with the notion that Notch signaling is important for maintaining the NPC population. Hes 5 expression is reduced in Notch1-null mutants and PS1-null mice, whereas Hes 1 expression is not affected in these mutant mice $[12,13,22]$. Nevertheless, Hes 1 is a primary Notch/ CBF1 target $[39,40]$ and promotes the cell cycle by suppressing p27Kip, a CDK inhibitor [41]. Expression of both Hes 1 and Hes 5 is significantly decreased in PS CDKO mice, suggesting that the presence of either PS1 or PS2 is sufficient for Hes 1 expression. When Hes 1 and Hes 5 were both mutated, complete loss of neural stem cells was observed [42]. This suggests that the more efficient blocking of Hes1 and Hes 5 expression in PS cDKO mice may be the main cause underlying the severe depletion of NPCs. However, substantial levels of Hes 1 and Hes 5 were still observed in $P S$ cDKO mice, suggesting the existence of presenilinindependent mechanisms for the regulation of Notch signaling $[43,44]$ or Notch-independent regulation of Hes1 expression $[45,46]$.

Notch signaling is important for the regulation of symmetric versus asymmetric cell division of neural stem cells $[47,48]$. The precise control of this symmetric/asymmetric cell division is essential not only for the nervous system to reach its mature size but also for its proper composition [10,49-51]. Recent reports have shown that two negative modulators of Notch signaling, Numb and Numblike, are important for the maintenance of neural progenitor cells in both earlier stages [52] and later stages [53,54] of neurogenesis in mouse forebrain development. The function of Numb/Numblike in neural progenitor cells is still unclear, because two very similar studies reported opposite results for NPC maintenance; one found more NPCs [53], whereas the other found fewer NPCs [54]. The conclusion of our current study that PS and perhaps Notch signal is required for NPCs to remain in the cell cycle is consistent with the result of the report by Li et al. [53]. Because the numb/numblike mutant mice also showed depletion of neural progenitor cells at early stages of neurogenesis [52], it is not yet clear regarding the function of Numb/Numblike in the maintenance of NPC population. Further detailed study is warranted to clarify the functional relation of these molecules in NPC maintenance.

\section{Presenilins in brain hemorrhages}

One of the surprising phenotypes of PS $\mathrm{CDKO}$ mice is the severe hemorrhage in the entire brain. In PS $\mathrm{cDKO}$ embryos, hemorrhages are first seen at E14.5 in small numbers of the embryos and by E15.5 spread to the entire brain in all embryos. Nakajima et al. [55] suggested a new function of PS1 in the endothelial cell of blood vessels based on the study using PS1 null mice. In the NPCrestricted PS cDKO mice, PS1 is apparently not eliminated in the mesoderm-derived blood vessel endothelial cells
[26,56]. Furthermore, cerebral hemorrhages were not found in NPC-restricted PS1 cKO embryonic brains [53]. These findings argue against the cause of the hemorrhage in PS CDKO being the possible leakage of the Nestin-Cre transgene expression in endothelial cells. The generation of all cell types in the cortex occurs in temporally distinct, albeit overlapping, phases - neurons are generated first (peaking at E14 and finishing perinatally), followed by astrocytes (starting at E13, peaking at P1, finishing by P10), and then oligodendrocytes (starting at E17 and continuing until adulthood) [57,58]. Owing to the severe and almost complete depletion of neural progenitor cells between E12.5 and E15.5, the PS cDKO brain may not generate enough astrocytes. Because astrocytes regulate formation of the blood-brain barrier through direct interaction with endothelial cells or by secreting the growth factors, the absence of astrocytes may result in defects in the formation of the blood-brain barrier [59-62]. The related mutant mice (numb/numblike cDKO and PS1 cKO) that harbor later and milder depletion of neural progenitor cells have not shown cerebral hemorrhages. This suggests that the early depletion of the neural progenitor cells followed by the loss of astrocytes may be the cause of the hemorrhage in the PS CDKO brain.

\section{Methods \\ Mice}

The generation of neural specific PS1 cKO mice using Nestin-Cre transgenic and floxed PS1 mice $[63,64]$ was described previously [26]. NPC-PS CDKO mice were generated by crossing the NPC-PS1 cKO mice to the PS2-/background. Specifically, NPC-PS cDKO (fPS1 $1 / f P S 1$;Nestin-Cre;PS2-/-, $f P S 1^{\triangle}$ represents a germ-line deletion of the floxed PS1 locus) mice used in the study were generated by crossing male $f P S 1^{\triangle} /+$;Nestin-Cre;PS2-/- mice with female fPS1/fPS1;PS2-/-. Since the floxed PS1 locus is linked to the Nestin-Cre transgene on the same chromosome, we were able to obtain NPC-PS cDKO (fPS1 ${ }^{\triangle} /$ fPS1;Nestin-Cre;PS2-/-) and littermate control (fPS1/+; $P S 2-/-)$ embryos at equal ratio. Animal breeding and experiment protocols were in accordance with the National Institute of Health Guidelines for use of live animals and approved by the Harvard Medical Area (HMA) Standing Committee of Animals.

\section{Preparation of embryos and brain sections}

After embryos were fixed in $4 \%$ paraformaldehyde at $4{ }^{\circ} \mathrm{C}$ for $1.5 \mathrm{~h}$ (E11.5) or $2 \mathrm{~h}$ (E12.5 and later stages), they were cryoprotected and embedded in OCT (Sakura Fine Technical) for frozen sections or dehydrated and embedded in paraffin for paraffin sections. For the S-phase labeling, the pregnant mice were injected intraperitoneally with BrdU/ PBS $(70 \mathrm{mg} / \mathrm{kg}$ body weight; Sigma) $30 \mathrm{~min}$ before the dissection. For the cell cycle exit experiments, BrdU was injected into the pregnant mice $24 \mathrm{~h}$ before the dissection. 


\section{Immunostaining and in situ hybridization}

For immunostainings, sections were blocked with a blocking solution containing 1\% BSA, 3\% goat serum, and $0.1 \%$ Triton $\mathrm{X}-100$ for $3 \mathrm{~h}$ at room temperature and incubated with the desired primary antibodies overnight at room temperature. The following primary antisera or antibodies were used: anti-TUJ-1 antibody (1:400, Babco), anti-phospho histone 3 (1:100, Santa Cruz Biotechnology). For immunohistochemistry, the secondary antibody labeled with biotin (1:400, Vector Labs) was incubated, and the ABC complex (Vector Labs) incubation followed. The staining was performed using the DAPI kit (Vector Labs) or AP Purple (Roche). For the fluorescence staining of the tissues, the primary antibody-treated sections were incubated with the appropriate Alexi Fluor 488- or Alexi Fluor 594-conjugated secondary antibodies (1:300, Molecular Probes) for $2 \mathrm{~h}$ at room temperature. Images were viewed on a Zeiss confocal laser scanning microscope and analyzed by using LSM 510 software. In situ hybridization of brain sections was performed as described previously [22] using the digoxygenin-labeled riboprobes. The Hes1, Hes5, and Dll1 riboprobes were described previously [22]. All statistical analyses of the counted cells were performed using Microsoft Excel software.

\section{Interkinetic nuclear migration and cell cycle reentering assay}

For S-Phase nuclei staining, the BrdU injected pregnant mice were dissected and the embryos were harvested at E13.5 or E14.5. The frozen sections were stained with an anti-BrdU antibody for S-Phase labeling. The pictures of stained slides were taken and the VZ were divided into 11 bins. The S-phase nuclei in each bin with a width of 500 $\mu \mathrm{m}$ were counted, and the numbers of the nuclei and their positions were shown in the diagram. The M-phase nuclei, which were stained with an anti-phospho-histone 3 antibody, were counted in dorsolateral corte $\mathrm{x}$ sections with a width of $750 \mu \mathrm{m}$. The portion of cells that re-enter cell cycle were calculated as following: The number of cells labeled with both BrdU and Ki67 (yellow, re-entered cell cycle) was divided by the total number of BrdU stained cells (green, BrdU+/Ki67- and yellow, BrdU+/Ki67+) 24 h after BrdU pulse labeling.

\section{Cell cycle parameters calculation}

Analysis of cell cycle kinetics in the cortex using cumulative BrdU-labeling procedures were performed as described previously [5] with slight modification. Briefly, BrdU pulses (70 mg/kg body weight) were given to pregnant dams every $2 \mathrm{~h}$ for up to $8 \mathrm{~h}$. Under these conditions, all nuclei passing through the S-phase will be labeled. Dams at the age of E13.5 were sacrificed 0.5, 1.5, 2.5, 4.5 and $8.5 \mathrm{~h}$ after the first injection. The embryos were fixed for $2 \mathrm{~h}$ in $4 \%$ paraformaldehyde, paraffin-embedded and processed to reveal BrdU immunoreactivity. The proportions of cells in the proliferative zone that were BrdU labeled were counted in $400 \mu \mathrm{m}$ wide strips throughout the telencephalon.

Labeling index (LI; labeled cells as a proportion of total cells) was calculated for the ventricular zone after the sections were stained with an anti BrdU antibody. After the staining, the labeling index at each time point was calculated as the number of BrdU-positive nuclei divided by the total nuclei count in the ventricular zone. The resulting data were then used to determine the time of BrdU labeling needed to reach the maximum value of BrdUstained nuclei, which corresponds to the total cell cycle length subtracted by the length of S phase (Tc-Ts).

\section{Quantitative real-time RT-PCR}

At E13.5, cortexes were collected for the preparation of total RNA using Tri reagent (Sigma). The cDNA was synthesized using the Superscript II first-strand cDNA synthesis system (Gibco BRL). Oligonucleotide primers were designed using Primer Express software 1.0 (Applied Biosystems). The specificity of primers was determined by gel electrophoresis of PCR products to ensure a single band with predicted size. Quantitative PCR reaction was performed using SYBR Green on an ABI PRISM 7700 Sequence Detection System (Applied Biosystems). Relative quantification of gene expression was performed using the comparative CT method according to manufacturer's recommended protocol (User Bulletin \#2, ABI PRISM 7700 Sequence Detection System, Perkin-Elmer). Levels of target mRNA were normalized using 18S rRNA. The change of the expression of a target gene in the PS cDKO embryonic brain relative to the littermate control was calculated as: Fold change $=2-(\Delta \mathrm{CT}, \mathrm{Tg}-\Delta \mathrm{CT}$, control $)$.

\section{Competing interests}

The author(s) declare that they have no competing interests.

\section{Authors' contributions}

WYK planned and performed the experiments and wrote the paper, JS supervised the project and wrote the paper. All authors have read and approved the final manuscript.

\section{Acknowledgements}

The authors thank Drs. Beglopoulos and Wines-Samuelson and other members of the Shen laboratory for invaluable help and discussions.

\section{References}

I. Sidman RL, Miale IL, Feder N: Cell proliferation and migration in the primitive ependymal zone: an autoradiographic study of histogenesis in the nervous system. Exp Neurol 1959, I:322-333.

2. Altman SABJ: Neocortical Development. New York, Raven Press; 1991.

3. Takahashi T, Goto T, Miyama S, Nowakowski RS, Caviness VS Jr.: Sequence of neuron origin and neocortical laminar fate: rela- 
tion to cell cycle of origin in the developing murine cerebral wall. J Neurosci 1999, I 9(23): 10357-I037I.

4. Takahashi T, Nowakowski RS, Caviness VS Jr.: Early ontogeny of the secondary proliferative population of the embryonic murine cerebral wall. J Neurosci 1995, 15(9):6058-6068.

5. Takahashi T, Nowakowski RS, Caviness VS Jr.: Cell cycle parameters and patterns of nuclear movement in the neocortical proliferative zone of the fetal mouse. J Neurosci 1993, I3(2):820-833.

6. Temple S: The development of neural stem cells. Nature 200I, 4|4(6859): I I2-II7.

7. Anderson DI: Stem cells and pattern formation in the nervous system: the possible versus the actual. Neuron 200I, 30(I): 19-35.

8. Qian X, Davis AA, Goderie SK, Temple S: FGF2 concentration regulates the generation of neurons and glia from multipotent cortical stem cells. Neuron 1997, I 8(I):8I-93.

9. Qian X, Shen Q, Goderie SK, He W, Capela A, Davis AA, Temple S: Timing of CNS cell generation: a programmed sequence of neuron and glial cell production from isolated murine cortical stem cells. Neuron 2000, 28(I):69-80.

10. Shen Q, Zhong W, Jan YN, Temple S: Asymmetric Numb distribution is critical for asymmetric cell division of mouse cerebral cortical stem cells and neuroblasts. Development 2002, I 29(20):4843-4853

II. Hitoshi S, Alexson T, Tropepe V, Donoviel D, Elia AJ, Nye JS, Conlon RA, Mak TW, Bernstein A, van der Kooy D: Notch pathway molecules are essential for the maintenance, but not the generation, of mammalian neural stem cells. Genes Dev 2002, 16(7):846-858.

12. Lutolf $S$, Radtke F, Aguet $M$, Suter $U$, Taylor $V$ : Notch I is required for neuronal and glial differentiation in the cerebellum. Development 2002, I 29(2):373-385.

13. de la Pompa JL, Wakeham A, Correia KM, Samper E, Brown S, Aguilera RJ, Nakano T, Honjo T, Mak TW, Rossant J, Conlon RA: Conservation of the Notch signalling pathway in mammalian neurogenesis. Development 1997, | 24(6): | |39-1 | 48.

14. Takahashi T, Nowakowski RS, Caviness VS Jr.: Interkinetic and migratory behavior of a cohort of neocortical neurons arising in the early embryonic murine cerebral wall. J Neurosci 1996, 16(18):5762-5776.

15. Caric D, Gooday D, Hill RE, McConnell SK, Price DJ: Determination of the migratory capacity of embryonic cortical cells lacking the transcription factor Pax-6. Development 1997, I 24(24):5087-5096.

16. Hutton M, Hardy J: The presenilins and Alzheimer's disease. Hum Mol Genet 1997, 6:1639-1646.

17. Wines-Samuelson M, Shen J: Presenilins in the developing, adult, and aging cerebral cortex. Neuroscientist 2005, I I(5):44I-45I.

18. Yoon K, Gaiano N: Notch signaling in the mammalian central nervous system: insights from mouse mutants. Nat Neurosci 2005, 8(6):709-7I5.

19. Artavanis-Tsakonas S, Rand MD, Lake RJ: Notch signaling: cell fate control and signal integration in development. Science 1999 , 284(54I5): $770-776$

20. Justice NJ, Jan YN: Variations on the Notch pathway in neural development. Curr Opin Neurobiol 2002, I 2:64-70.

21. Schuurmans C, Guillemot F: Molecular mechanisms underlying cell fate specification in the developing telencephalon. Curr Opin Neurobiol 2002, I 2(1):26-34.

22. Handler $M$, Yang $X$, Shen J: Presenilin-I regulates neuronal differentiation during neurogenesis. Development 2000, 1 27:2593-2606.

23. Shen J, Bronson RT, Chen DF, Xia W, Selkoe DJ, Tonegawa S: Skeletal and CNS defects in presnilin-I deficient mice. Cell 1997, 89:629-639.

24. Steiner H, Duff K, Capell A, Romig H, Grim MG, Lincoln S, Hardy J, Yu X, Picciano M, Fechteler K, Citron M, Kopan R, Pesold B, Keck S, Baader M, Tomita T, Iwatsubo T, Baumeister R, Haass C: A loss of function mutation of presenilin-2 interferes with amyloid Bpeptide production and Notch signaling. J Biol Chem 1999, 274:28669-28673.

25. Donoviel DB, Hadjantonakis A, Ikeda M, Zheng H, St George Hyslop $P$, Bernstein A: Mice lacking both presenilin genes exhibit early embryonic patterning defects. Genes \& Dev 1999, I3:280 I-28I0.
26. Wines-Samuelson M, Handler M, Shen J: Role of presenilin-I in cortical lamination and survival of Cajal-Retzius neurons. Dev Biol 2005, 277(2):332-346.

27. Saura CA, Choi SY, Beglopoulos V, Malkani S, Zhang D, Shankaranarayana Rao BS, Chattarji S, Kelleher RJ 3rd, Kandel ER, Duff K, Kirkwood A, Shen J: Loss of presenilin function causes impairments of memory and synaptic plasticity followed by age-dependent neurodegeneration. Neuron 2004, 42(I):23-36.

28. Hayes NL, Nowakowski RS: Exploiting the dynamics of S-phase tracers in developing brain: interkinetic nuclear migration for cells entering versus leaving the S-phase. Developmental neuroscience 2000, 22(I-2):44-55.

29. Nowakowski RS, Lewin SB, Miller MW: Bromodeoxyuridine immunohistochemical determination of the lengths of the cell cycle and the DNA-synthetic phase for an anatomically defined population. J Neurocytol 1989, 18(3):3।I-3|8.

30. Yuasa S, Nakajima M, Aizawa H, Sahara N, Koizumi K, Sakai T, Usami M, Kobayashi S, Kuroyanagi H, Mori H, Koseki H, Shirasawa T: Impaired cell cycle control of neuronal precursor cells in the neocortical primordium of presenilin- I-deficient mice. J Neurosci Res 2002, 70(3):50I-5I3.

31. Takahashi T, Nowakowski RS, Caviness VS Jr.: The cell cycle of the pseudostratified ventricular epithelium of the embryonic murine cerebral wall. J Neurosci 1995, 15(9):6046-6057.

32. Sauer FC: Mitosis in the neural tube. 1935, 62(2):377-405.

33. Soriano S, Kang DE, Fu M, Pestell R, Chevallier N, Zheng H, Koo EH: Presenilin I negatively regulates beta-catenin/T cell factor/ lymphoid enhancer factor-I signaling independently of betaamyloid precursor protein and notch processing. I Cell Biol 200I, I $52(4): 785-794$.

34. Kang DE, Soriano S, Xia X, Eberhart CG, De Strooper B, Zheng H, Koo EH: Presenilin couples the paired phosphorylation of beta-catenin independent of axin: implications for beta-catenin activation in tumorigenesis. Cell 2002, I 10(6):75I-762.

35. Chenn A, Walsh CA: Regulation of cerebral cortical size by control of cell cycle exit in neural precursors. Science 2002 , 297(5580):365-369.

36. Parks AL, Curtis D: Presenilin diversifies its portfolio. Trends Genet 2007, 23(3): 140-150.

37. Yang X, Klein R, Tian X, Cheng HT, Kopan R, Shen J: Notch activation induces apoptosis in neural progenitor cells through a p53-dependent pathway. Dev Biol 2004, 269(I):8I-94.

38. Androutsellis-Theotokis A, Leker RR, Soldner F, Hoeppner DJ, Ravin R, Poser SW, Rueger MA, Bae SK, Kittappa R, McKay RD: Notch signalling regulates stem cell numbers in vitro and in vivo. Nature 2006, 442(7 I 04):823-826.

39. Ishibashi M, Ang SL, Shiota K, Nakanishi S, Kageyama R, Guillemot F: Targeted disruption of mammalian hairy and Enhancer of split homolog-I (HES-I) leads to up-regulation of neural helix-loop-helix factors, premature neurogenesis, and severe neural tube defects. Genes Dev 1995, 9(24):3।36-3।48.

40. Kageyama R, Ohtsuka $T$ : The Notch-Hes pathway in mammalian neural development. Cell Res 1999, 9(3):179-188.

4I. Murata K, Hattori M, Hirai N, Shinozuka Y, Hirata H, Kageyama R, Sakai T, Minato N: HesI directly controls cell proliferation through the transcriptional repression of p27Kipl. Mol Cell Biol 2005, 25(10):4262-427I.

42. Ohtsuka T, Sakamoto M, Guillemot F, Kageyama R: Roles of the basic helix-loop-helix genes HesI and Hes5 in expansion of neural stem cells of the developing brain. J Biol Chem 200I, 276(32):30467-30474.

43. Berechid BE, Kitzmann M, Foltz DR, Roach AH, Seiffert D, Thompson LA, Olson RE, Bernstein A, Donoviel DB, Nye JS: Identification and characterization of presenilin-independent Notch signaling. J Biol Chem 2002, 277(10):8154-8I65.

44. Huppert SS, llagan MX, De Strooper B, Kopan R: Analysis of notch function in presomitic mesoderm suggests a gamma-secretase-independent role for presenilins in somite differentiation. Dev Cell 2005, 8(5):677-688.

45. Feder JN, Jan LY, Jan YN: A rat gene with sequence homology to the Drosophila gene hairy is rapidly induced by growth factors known to influence neuronal differentiation. Mol Cell Biol 1993, I3(1): 105-113.

46. Solecki DJ, Liu XL, Tomoda T, Fang Y, Hatten ME: Activated Notch2 signaling inhibits differentiation of cerebellar gran- 
ule neuron precursors by maintaining proliferation. Neuron 200I, 3 I (4):557-568.

47. Roegiers F, Younger-Shepherd S, Jan LY, Jan YN: Two types of asymmetric divisions in the Drosophila sensory organ precursor cell lineage. Nat Cell Biol 200I, 3(I):58-67.

48. Ceron J, Gonzalez C, Tejedor FJ: Patterns of cell division and expression of asymmetric cell fate determinants in postembryonic neuroblast lineages of Drosophila. Dev Biol 200I, 230(2): $125-138$.

49. Sommer $L$, Rao $M$ : Neural stem cells and regulation of cell number. Prog Neurobiol 2002, 66(I): I-I8.

50. Wodarz A, Huttner WB: Asymmetric cell division during neurogenesis in Drosophila and vertebrates. Mech Dev 2003, I 20(I I): I 297-I309.

5I. Matsuzaki F: Asymmetric division of Drosophila neural stem cells: a basis for neural diversity. Curr Opin Neurobiol 2000, I O(I):38-44.

52. Petersen PH, Zou K, Hwang JK, Jan YN, Zhong W: Progenitor cell maintenance requires numb and numblike during mouse neurogenesis. Nature 2002, 4 I 9(69 I 0):929-934.

53. Li HS, Wang D, Shen Q, Schonemann MD, Gorski JA, Jones KR, Temple S, Jan LY, Jan YN: Inactivation of Numb and Numblike in embryonic dorsal forebrain impairs neurogenesis and disrupts cortical morphogenesis. Neuron 2003, 40(6): II05-III8.

54. Petersen PH, Zou K, Krauss S, Zhong W: Continuing role for mouse Numb and Numbl in maintaining progenitor cells during cortical neurogenesis. Nat Neurosci 2004, 7(8):803-8II.

55. Nakajima M, Yuasa S, Ueno M, Takakura N, Koseki H, Shirasawa T: Abnormal blood vessel development in mice lacking presenilin- I. Mech Dev 2003, I 20(6):657-667.

56. Tronche F, Kellendonk C, Kretz O, Gass P, Anlag K, Orban PC, Bock $R$, Klein R, Schutz G: Disruption of the glucocorticoid receptor gene in the nervous system results in reduced anxiety. Nat Genet 1999, 23(I):99-103.

57. Sauvageot CM, Stiles CD: Molecular mechanisms controlling cortical gliogenesis. Curr Opin Neurobiol 2002, I 2(3):244-249.

58. Bayer SA, Altman J: Development of the endopiriform nucleus and the claustrum in the rat brain. Neuroscience 1991, 45(2):39|-4I|2.

59. Engelhardt B, Conley FK, Kilshaw PJ, Butcher EC: Lymphocytes infiltrating the CNS during inflammation display a distinctive phenotype and bind to VCAM-I but not to MAdCAM-I. Int Immunol 1995, 7(3):48I-49I.

60. Janzer RC, Raff MC: Astrocytes induce blood-brain barrier properties in endothelial cells. Nature 1987, 325(6 I0I):253-257.

61. Rieckmann P, Engelhardt B: Building up the blood-brain barrier. Nat Med 2003, 9(7):828-829.

62. Lee SW, Kim WJ, Choi YK, Song HS, Son MJ, Gelman IH, Kim YJ, Kim $\mathrm{KW}$ : SSeCKS regulates angiogenesis and tight junction formation in blood-brain barrier. Nat Med 2003, 9(7):900-906.

63. $\mathrm{Yu} \mathrm{H}$, Kessler J, Shen J: Heterogeneous populations of ES cells in the generation of a floxed Presenilin-I allele. Genesis 2000, 26(I):5-8.

64. Yu H, Saura CA, Choi SY, Sun LD, Yang X, Handler M, Kawarabayashi T, Younkin L, Fedeles B, Wilson MA, Younkin S, Kandel ER, Kirkwood $A$, Shen J: APP processing and synaptic plasticity in presenilinI conditional knockout mice. Neuron 200 I, 3 I(5):7|3-726.
Publish with Biomed Central and every scientist can read your work free of charge

"BioMed Central will be the most significant development for disseminating the results of biomedical research in our lifetime. "

Sir Paul Nurse, Cancer Research UK

Your research papers will be:

- available free of charge to the entire biomedical community

- peer reviewed and published immediately upon acceptance

- cited in PubMed and archived on PubMed Central

- yours - you keep the copyright
BioMedcentral 